06,13

\title{
Структурные характеристики выращенных методом RF-катодного напыления тонких пленок $\mathrm{Sr}_{0.61} \mathrm{Ba}_{0.39} \mathrm{Nb}_{2} \mathrm{O}_{6} / \mathrm{MgO}(001)$
}

\author{
() А.В. Павленко ${ }^{1,2}$, Д.В. Стрюков ${ }^{1}$, Л.И. Ивлева ${ }^{3}$, А.П. Ковтун ${ }^{1}$, К.М. Жидель ${ }^{1}$, П.А. Лыков ${ }^{3}$ \\ ${ }^{1}$ Федеральный исследовательский центр Южный научный центр РАН, \\ Ростов-на-Дону, Россия \\ ${ }^{2}$ Научно-исследовательский институт фризики Южного федерального университета, \\ Ростов-на-Дону, Россия \\ ${ }^{3}$ Институт общей фризики им. А.М. Прохорова РАН, \\ Москва, Россия. \\ E-mail: Antvpr@mail.ru
}

Поступила в Редакцию 24 августа 2020 г.

В окончательной редакции 24 августа 2020 г.

Принята к публикации 25 августа 2020 г.

\begin{abstract}
Методом RF-катодного распыления в атмосфере кислорода получены тонкие пленки конгруэнтного состава системы твердых растворов ниобатов бария-стронция $\mathrm{Sr}_{0.61} \mathrm{Ba}_{0.39} \mathrm{Nb}_{2} \mathrm{O}_{6}$ ( $\mathrm{SBN}: 61$ ) толщинами от 30 до $630 \mathrm{~nm}$ на подложке $\mathrm{MgO}(001)$. По данным рентгендифракционного анализа установлено, что пленки являются беспримесными и монокристаллическими. В пленках практически отсутствуют деформации элементарной ячейки в плоскости сопряжения и присутствуют растягивающие напряжения в направлении нормали к поверхности, которые увеличиваются при уменьшении толщины пленки. Диэлектрические измерения свидетельствуют о высокой управляемости в пленках.
\end{abstract}

Ключевые слова: тонкие пленки, ниобат бария-стронция, SBN, деформация элементарной ячейки.

DOI: $10.21883 /$ FTT.2021.02.50473.174

\section{1. Введение}

Твердые растворы (TP) $\mathrm{Sr}_{x} \mathrm{Ba}_{1-x} \mathrm{Nb}_{2} \mathrm{O}_{6} \quad(\mathrm{SBNx})-$ представители класса одноосных сегнетоэлектриковрелаксоров со структурой незаполненной тетрагональной калий-вольфрамовой бронзы (ТКВБ) [1,2], являются перспективными материалами для применения в МЭМС, электрооптических и оптико-акустических элементах, пироэлектрических датчиках. Интерес к ним обусловлен высокими электрооптическими коэффициентами $\left(r_{33}=1340 \mathrm{pm} / \mathrm{V}\right.$ для $\mathrm{SBN}: 75, r_{33}=235 \mathrm{pm} / \mathrm{V}$ для $\mathrm{SBN}: 61)$, во много раз превышающими электрооптические коэффициенты кристаллов группы дигидрофосфата калия и ниобата лития, высокими пироэлектрическими коэффициентами $\left(0.28 \mu \mathrm{C} /\left(\mathrm{cm}^{2} \cdot \mathrm{K}\right)\right.$ для $\mathrm{SBN}: 75$; $0.065 \mu \mathrm{C} /\left(\mathrm{cm}^{2} \cdot \mathrm{K}\right)$ для $\left.\mathrm{SBN}: 61\right)$ [3]. Учитывая стремление к миниатюризации изделий современной функциональной электроники, в последние десятилетия в физическом материаловедении стало уделяться большое внимание теоретико-экспериментальным исследованиям свойств тонких пленок $\mathrm{SBNx}$, выращенных на диэлектрических $\left(\mathrm{MgO}, \mathrm{Al}_{2} \mathrm{O}_{3}, \mathrm{SrTiO}_{3}\right)$ и полупроводниковых подложках ( $\mathrm{Si} n$ - и $p$-типа). К настоящему времени, монокристаллические тонкие пленки SBNx успешно получены металлорганическим методом [4] и магнетронным осаждением [5], импульсным лазерным осаждением (ИЛО) [6], а так же RF-катодным напылением [7,8]. При эпитаксиальном росте на $\mathrm{MgO}(001)$ пленка $\mathrm{SBNx}$ кристаллизуется с хорошо ориентированной полярной осью [001] в направлении перпендикуляра к плоско- сти подложки (ось [001] MgO), а в плоскости сопряжения наблюдается несколько вариантов ориентаций кристаллографической оси [100] SBN относительно оси $[100] \mathrm{MgO}: 0^{\circ}, \pm 18.43^{\circ}, \pm 30.96^{\circ}$ [4-7]. В [4] показано, что при использовании ИЛО для SBNx при $x$ от 0.35 до 0.55 присутствуют все три ориентации (причем больше всего $\left.\pm 30.96^{\circ}\right)$, а при концентрации $\mathrm{Sr}$ от 0.55 до 0.75 преобладает одна ориентация $\pm 18.43^{\circ}$, а две другие практически подавляются. В целом, эти закономерности подтверждаются экспериментальными результатами различных научных групп, в том числе и нашей $[8,9]$. Однако, к настоящему времени в литературе практически отсутствуют результаты исследований зависимостей параметров структуры для пленок SBNx от толщины. Подобные исследования важных как с теоретической (изучение проявления размерных эффектов в структурах ТКВБ), так и с практической (в зависимости от области применения необходимы пленки различной толщины) точек зрения. В настоящей работе представлены результаты исследования структуры и свойств тонких пленок конгруэнтного состава $\mathrm{SBN}: 61$ толщинами от 30 до $630 \mathrm{~nm}$, выращенных на подложках $\mathrm{MgO}$ ориентации (001).

\section{2. Объекты. Методы получения и исследования}

Твердый раствор стехиометрического состава $\mathrm{Sr}_{0.61} \mathrm{Ba}_{0.39} \mathrm{Nb}_{2} \mathrm{O}_{6}$ был получен в Институте общей фи- 
зики им. А.М. Прохорова РАН методом твердофазного синтеза при температуре $1200^{\circ} \mathrm{C}$ из исходных компонентов $\mathrm{SrCO}_{3}, \mathrm{BaCO}_{3}, \mathrm{Nb}_{2} \mathrm{O}_{5}$ марки „ОСЧ“. Керамическая мишень $d=50 \mathrm{~mm} \quad$ и $h=3 \mathrm{~mm}$ была изготовлена в отделе ИМиНТ НИИ физики ЮФУ (спекание в воздушной атмосфере при $T=1350^{\circ} \mathrm{C}$ в течение $2 \mathrm{~h}$, относительная плотность полученной керамики $\sim 92 \%)$. Газоразрядное RF-напыление пленок SBN-61 толщиной от 30 до $630 \mathrm{~nm}$ на монокристаллические подложки (001) MgO производилось по технологии, описанной например в [7], на установке „Плазма 50-СЭ“ ЦКП НИИ физики ЮФУ. Начальная температура подложки $\mathrm{MgO}$ до включения разряда составляла $\sim 400^{\circ} \mathrm{C}$, а после включения устанавливалась в диапазоне $520-540^{\circ} \mathrm{C}$, давление чистого кислорода в камере -0.5 Torr, ВЧ мощность $110 \mathrm{~W}$, расстояние мишень подложка $-12 \mathrm{~mm}$. Толщина пленок рассчитывалась по времени напыления (скорость роста составляла $\sim 5.5-6 \mathrm{~nm} / \mathrm{min}$ и оценивалась на базе микроскопических измерений перпендикулярного поперечного скола контрольной группы образцов). Учитывая результаты работы [10], в рамках используемого метода состав пленок сохраняется, а легирование пленки конструкционными элементами не происходит.

Структурное совершенство пленок, параметры элементарной ячейки в направлении нормали к плоскости подложки, а также ориентационные соотношения между пленкой и подложкой устанавливались рентгенографированием на дифрактометре „ДРОН-4-07“ методом $\theta / 2 \theta$ (СuК $\alpha$ излучение) (ЦКП ЮНЦ РАН). Поверхность пленок анализировалась на сканирующем электронном микроскопе с автоэмиссионным катодом (FE SEM) Zeiss SUPRA 25 (кафедра „Нанотехнология“ физического факультета ЮФУ). Изображения зарегистрированы на внутрилинзовом детекторе вторичных электронов.

Для проведения диэлектрических измерений в направлении, перпендикулярном плоскости пленки, на свободную поверхность пленки SBN-61 через металлическую маску с отверстиями диаметром $180-200 \mu$ m осаждались электроды методом термического испарения $\mathrm{Al}$ в вакууме (в качестве адгезионного подслоя был использован (C). В качестве нижнего электрода выступал предварительно выращенный слой $\mathrm{SrRuO}_{3}$ толщиной $200 \mathrm{~nm}$, который, как и пленки SBN-61, напылялся по технологии [7] на установке „Плазма 50-СЭ“. Измерения вольт-фарадных характеристик $C(U)$ и поляризации от внешнего поля $P(U)$ осуществлялись на анализаторе TF Analyzer 2000 при комнатной температуре.

\section{3. Экспериментальные результаты и обсуждение}

На рис. 1,a представлены результаты рентгендифракционного анализа серии гетероструктур $\mathrm{SBN}-61 / \mathrm{MgO}(001)$ различной толщины. Во всех исследованных гетероструктурах не обнаружено следов
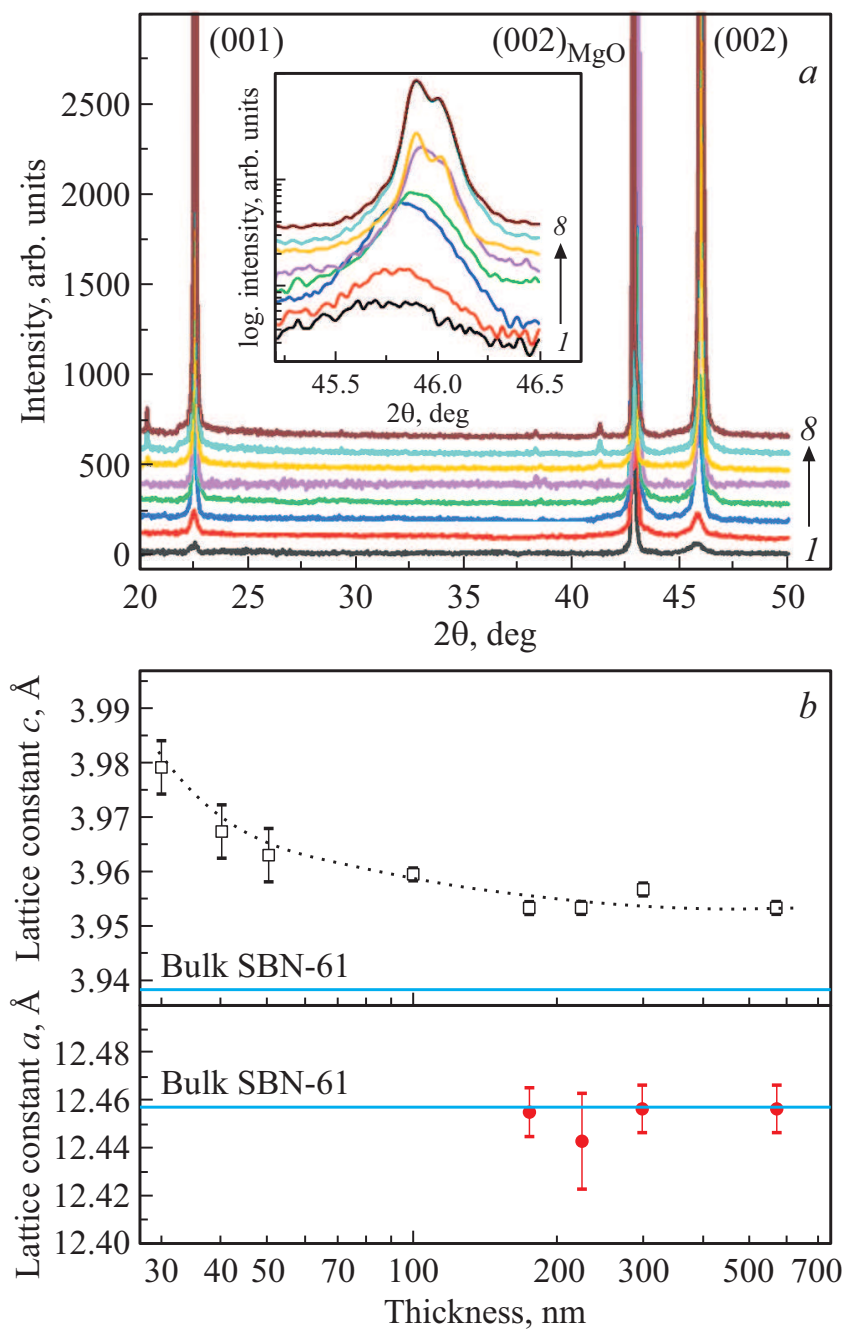

Рис. 1. а) $\theta-2 \theta$-рентгенограммы пленок $\mathrm{SBN}-61 / \mathrm{MgO}(001)$ различной толщины, где 1 - пленка толщиной $30 \mathrm{~nm}$; $2-41 \mathrm{~nm} ; 3-52 \mathrm{~nm} ; 4-107 \mathrm{~nm} ; 5-190 \mathrm{~nm} ; 6-245 \mathrm{~nm}$; $7-327 \mathrm{~nm} ; 8-630 \mathrm{~nm}$. На вставке более детально изображены рефлексы (002) соответствующих пленок. $b$ ) Зависимость параметров элементарных ячеек пленок $\mathrm{SBN}-61 / \mathrm{MgO}(001)$ от толщины.

примесных фаз, отмеченных в [4]. Доказательство эпитаксиального роста было получено из $\varphi$-сканирования отражений (221) и (311) пленки SBN-61 (рис. 2,a). На $\varphi$-сканировании отражения (221) пленки присутствуют восемь отражений, а на рентгенограмме (311) - двенадцать линий, среди которых 4 рефлекса с большой интенсивностью и 8 рефлексов с малой. Такое распределение интенсивностей на обеих рентгенограммах $\varphi$-сканирований (221) и (311) пленки SBN-61 можно объяснить наличием двух ориентационных доменов в пленке (рис. 2,b). Сравнивая угловые положения рефлексов $\varphi$-сканирования пленки с угловыми положениями рефлексов (113) подложки (рис. 2) установлено, что кристаллографические оси [001] данных ориентационных доменов пленок развернуты симметрично отно- 
сительно оси [001] подложки на углы $+18.4^{\circ}$ и $-18.4^{\circ}$. Получены следующие эпитаксиальные соотношения

$$
\begin{aligned}
& {[001] \mathrm{SBN}-61_{+18.4^{\circ}} \|[001] \mathrm{MgO} ;} \\
& {[010] \mathrm{SBN}-61_{+18.4^{\circ}} \|[\overline{130}] \mathrm{MgO},} \\
& {[100] \mathrm{SBN} 61_{+18.4^{\circ}} \|[310] \mathrm{MgO}} \\
& {[001] \mathrm{SBN}-61_{-18.4^{\circ}} \|[001] \mathrm{MgO} ;} \\
& {[010] \mathrm{SBN}-61_{-18.4^{\circ}} \|[130] \mathrm{MgO},} \\
& {[100] \mathrm{SBN}-61_{-18.4^{\circ}} \|[3 \overline{1} 0] \mathrm{MgO} .}
\end{aligned}
$$

Прецизионное исследование (001) рефлексов пленок выявило сдвиг положения максимумов с увеличением толщины пленки (вставка на рис. 1,a). Из положений максимумов отражений были определены параметры элементарной ячейки (рис. $1, b)$. Полученные параметры $c$ элементарной ячейки ТКВБ демонстрируют, что с увеличением толщины пленки происходит уменьшение параметра $c$, и при толщине $190 \mathrm{~nm}$ достигается минимум. Дальнейшее увеличение толщины до $630 \mathrm{~nm}$ не приводит к существенному изменению параметpa $c$. Параметр a в плоскости сопряжения подложкапленка измерен только для достаточно толстых пленок (> $190 \mathrm{~nm})$ с использованием асимметричной геометрии съемки. Этот параметр также не изменяется при увеличении толщины пленки от 190 до $630 \mathrm{~nm}$ и равен $a_{f}=12.45 \pm 0.01 \AA$. Из сравнения полученных параметров элементарной ячейки с параметрами объемного образца $\left(a_{b}=12.456 \AA ; c_{b}=3.936 \AA\right)$ видно, что элементарная ячейка пленки практически не имеет деформации в плоскости сопряжения и растянута вдоль оси $c$. С уменьшением толщины пленки деформация в направлении нормали к плоскости подложки $\left(\varepsilon_{33}=\left(c_{f}-c_{b}\right) / c_{b} \times 100 \%\right)$ увеличивается и достигает $\approx 1 \%$ для пленки толщиной $30 \mathrm{~nm}$. Величина же микродеформации $(\Delta c / c)$ слоя SBN-61, определенная из экспериментальных данных с использованием уравнения Стокса-Уилсона [11], с уменьшением толщины пленки с 630 до $30 \mathrm{~nm}$ возрастала с 0.001 до 0.007, т. е. степень дефектности пленки SBN-61 возрастала.

На рис. 3, в качестве примера, приведены в РЭМмикрофотографии пленок SBN-61 различной толщины. Их поверхность является однородной, включений примесных фаз, пор и каверн не наблюдалось, шероховатость достаточно низкой, что согласуется с [8], но по мере увеличения толщины пленки возрастает. Признаков наличия именно блочной структуры, сформированной выявленными ориентационными доменами, не выявлено. Совместно с результатами проведенного рентгендифракционного анализа, это, с нашей точки зрения, свидетельствует о том, что пленки были выращены по механизму Фольмера-Вебера [12]. Рост пленок в этом случае [13] происходит через начальное образование трехмерных зародышей, в дальнейшем разрастающихся в сплошную пленку на поверхности подложки $\mathrm{MgO}(001)$, формируя ростовые домены, выявленные нами по результатам

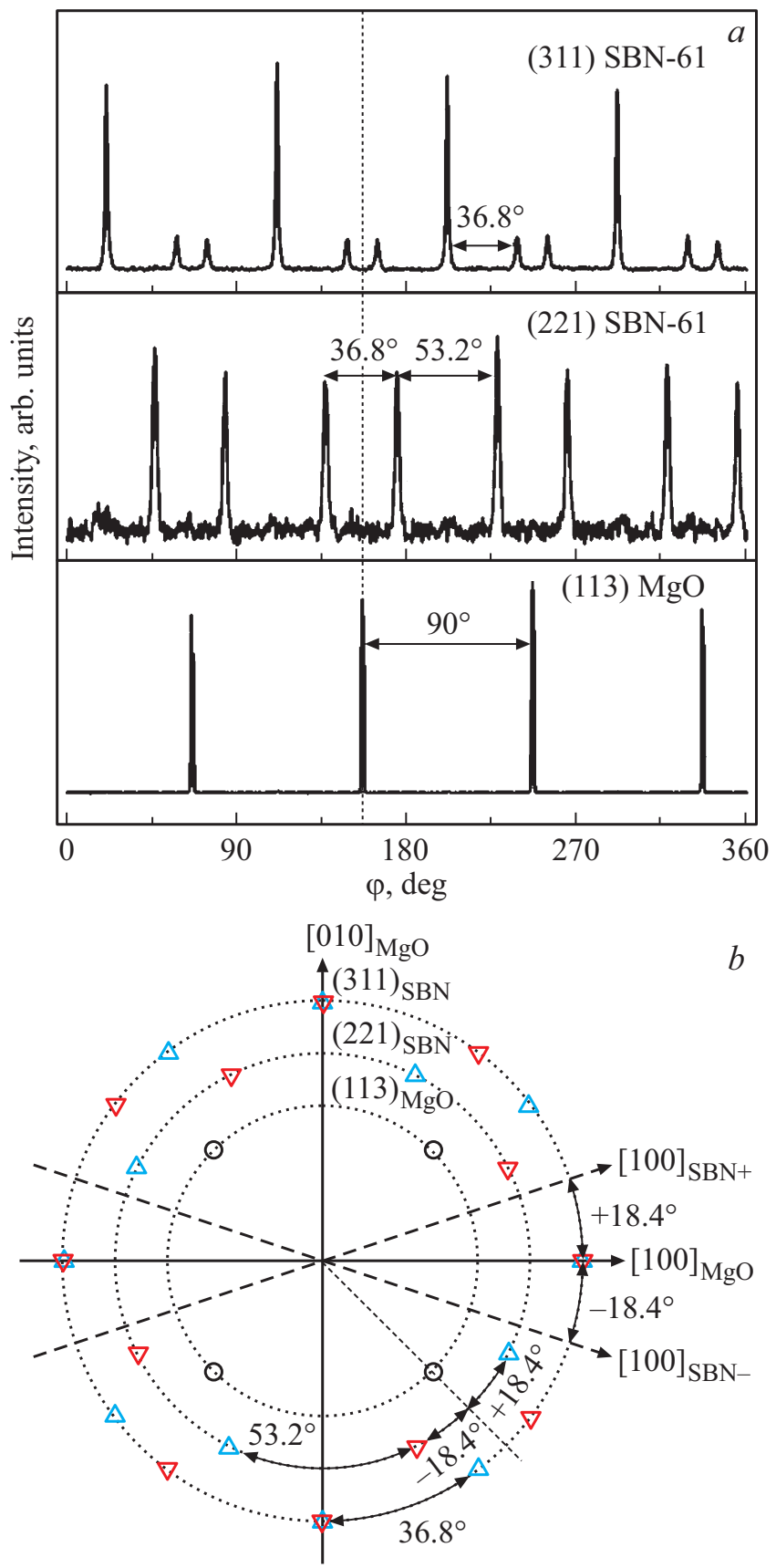

Рис. 2. a) Рентгенограммы $\varphi$-сканирования рефлексов (221), (311) пленки и (113) подложки для пленки $\mathrm{SBN}-61 / \mathrm{MgO}(001)$ толщиной $190 \mathrm{~nm}$. b) Схема относительной ориентации рефлексов (211) пленки SBN (треугольники) и (113) подложки $\mathrm{MgO}$ (кружки), где $\mathrm{SBN}+(\triangleleft)$ соответствует ориентационным доменам с разориентировкой $+18.43^{\circ}, \mathrm{SBN}-(\mathbf{v})$ соответствует $-18.43^{\circ}$.

рентгендифракционного анализа. Анализ величин интенсивности соответствующих линий для каждого из двух типов ростовых доменов свидетельствует о сопоставимости их количества в полученных пленках. Для обоих ориентационных доменов параметры решетки $c$ одинаковы, параметры решетки $a$ и $b$ в плоскости 
$a$
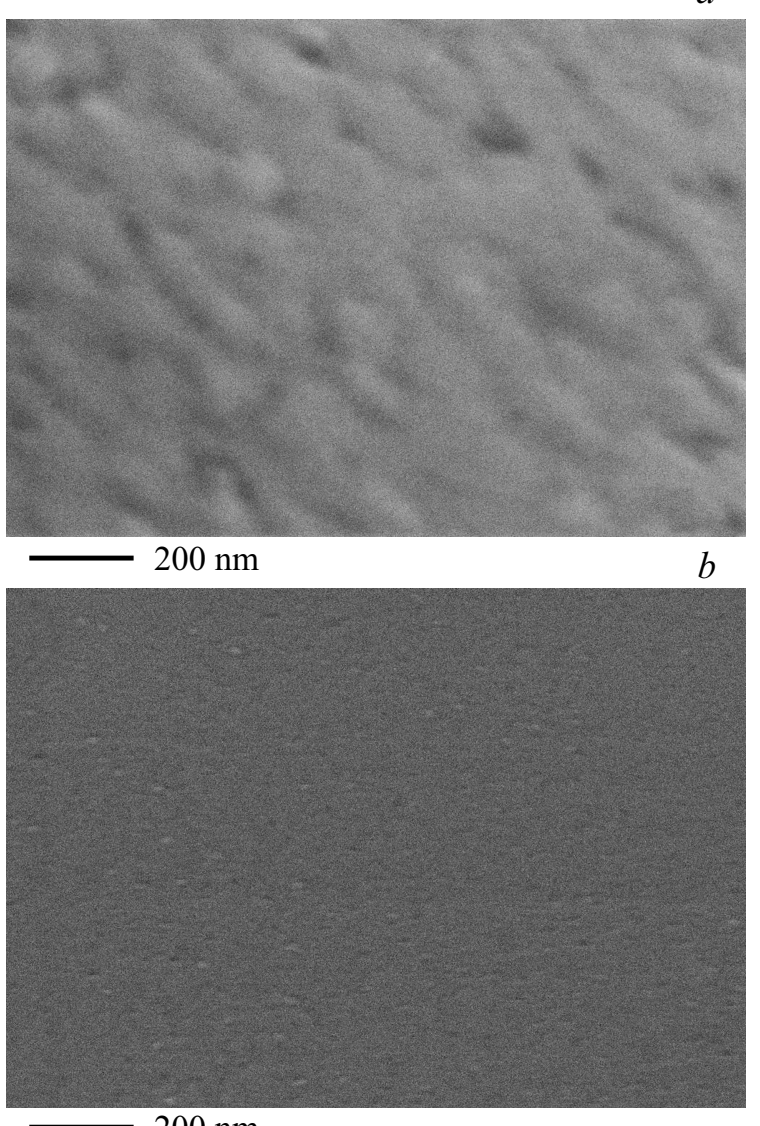

$200 \mathrm{~nm}$

Рис. 3. РЭМ-изображение поверхности пленок SBN-61 толщинами $245 \mathrm{~nm}(a)$ и $52 \mathrm{~nm}(b)$.

сопряжения равны между собой. В рамках точности эксперимента симметрия каждого из ориентационных доменов остается тетрагональной, то есть не отличается от объемного материала. Для всех пленок вертикальная разориентация не превышает $1^{\circ}$, а азимутальная разориентация меньше $3^{\circ}$.

В пленках с $h>190 \mathrm{~nm}$ кристаллическая структура практически не деформирована в плоскости сопряжения и растянута вдоль полярной „с“ оси, деформация элементарной ячейки не превышает $0.4 \%$. На рис. 4 в качестве примера в рамках данной работы приведены зависимости $C(U)$ и $P(U)$ гетероструктуры Al/SBN-61 $(h=630 \mathrm{~nm}) / \mathrm{SrRuO}_{3}(001) / \mathrm{MgO}(001)$. Фиксирование петли диэлектрического гистерезиса, форма которой является достаточно вытянутой, подтверждает наличие сегнетоэлектрических свойств в пленке SBN-61 (величинами коэрцитивного поля $U_{c} \sim 1 \mu \mathrm{C} / \mathrm{cm}^{2}$, остаточной поляризации $\left.P_{R} \sim 5 \mathrm{kV} / \mathrm{cm}\right)$, при этом асимметрия зависимости $P(U)$ свидетельствует о наличии внутреннего поля в пленке. Зависимость $C(U)$ имеет так же свойственную СЭ-структурам форму „бабочки“ и характеризуется наличием слабого гистерезиса и достаточно высокой управляемостью $(\sim 40 \%$ при $U=90 \mathrm{kV} / \mathrm{cm}$ на частоте измерительного электрического поля $100 \mathrm{kHz}$, период внешнего смещающего поля треугольной формы составлял $100 \mathrm{~s}$ ). Это обусловлено низким значением коэрцитивного поля. Наличие асимметрии $C(U)$ обусловлено, как и в случае зависимости $P(U)$, наличием внутреннего поля в пленке [14].

В пленках с $h<190 \mathrm{~nm}$ по мере уменьшения толщины деформация в направлении нормали к плоскости подложки увеличивается и достигает $\approx 1 \%$ для пленки толщиной $30 \mathrm{~nm}$. Это, учитывая результаты наших предыдущих работ $c$-ориентированных пленок ниобатов бариястронция других составов, а так же работ, посвященных монокристаллическим образцам (например [15]), позволяет ожидать в гетероструктурах $\mathrm{SBN}-61 /(001) \mathrm{MgO}$ с такими толщинами существенного изменения оптических, диэлектрических и пьезоэлектрических свойств, в частности - возрастания их оптической анизотропии [15] и роста температуры сегнетоэлектрического фазового перехода. Этому будут посвящены наши дальнейшие исследования.
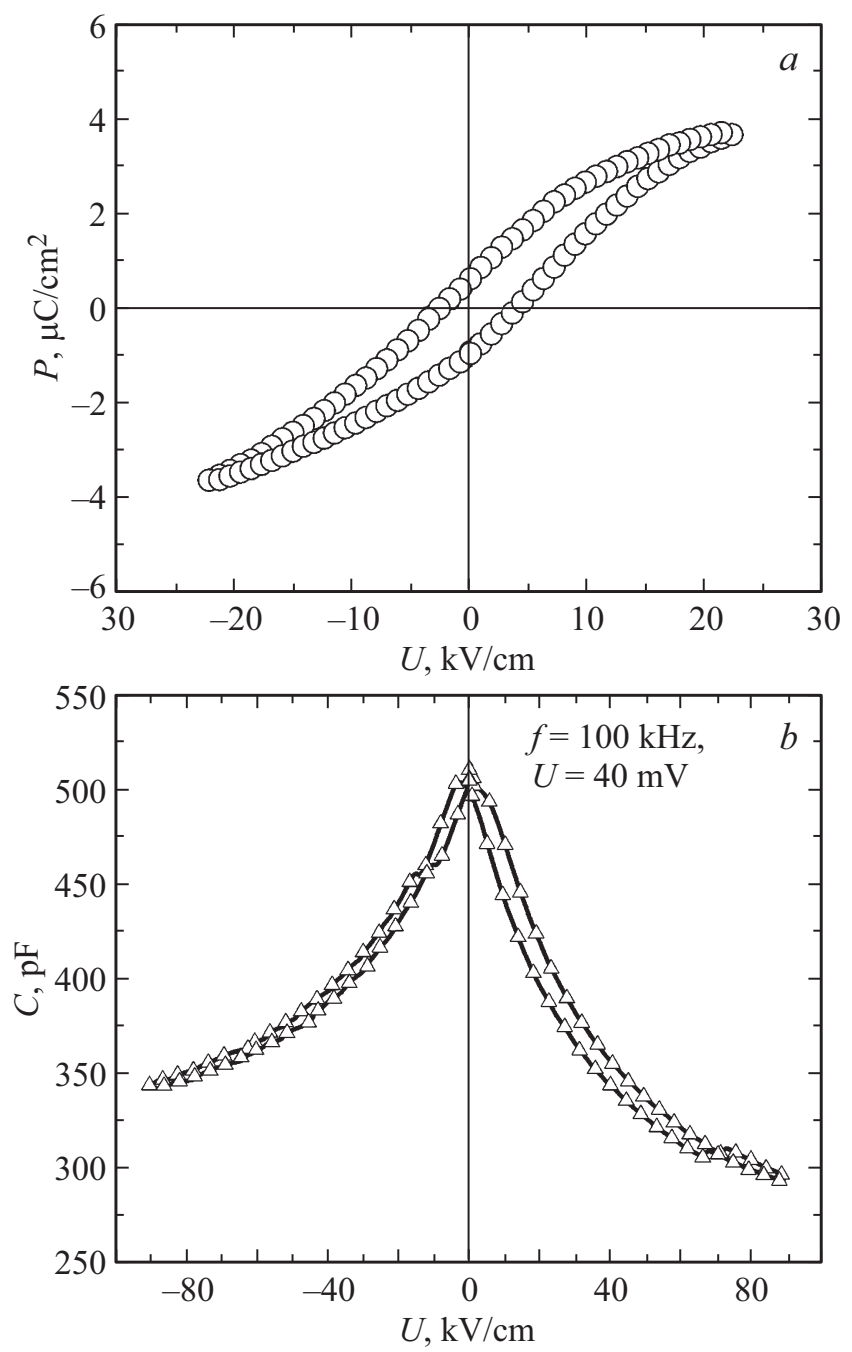

Рис. 4. Зависимости $P(U)$ и $C(U)$ для гетероструктуры $\mathrm{A} 1 / \mathrm{SBN}-61 / \mathrm{SrRuO}_{3}(200 \mathrm{~nm}) / \mathrm{MgO}(001)$. Частота измерительного электрического напряжения $C(U)$ с амплитудой $40 \mathrm{mV}$ составляла $100 \mathrm{kHz}$. 


\section{4. Выводы}

1. При исследовании методами рентгендифракционного анализа и электронной микроскопии выращенных по механизму Фольмера-Вебера на подложках оксида магния среза (001) тонких монокристаллических пленок SBN-61 толщинами от 30 до $630 \mathrm{~nm}$, выявлено наличие только двух типов ориентационных доменов, кристаллографические оси [001] которых развернуты симметрично относительно оси [001] подложки на углы $+18.4^{\circ}$ и $-18.4^{\circ}$.

2. Анализ зависимости параметров ячейки пленок от их толщины позволил выявить наличие критической толщины $190 \mathrm{~nm}$, обусловленной, скорее всего именно спецификой структуры ниобатов бария-стронция, заключающейся в наличии как пустот, так и вероятностным заполнением катионов бария и стронция структурных позиций. Выше критической деформация пленки от толщины не изменяется, а ниже - в направлении нормали к плоскости подложки возрастает и достигает $\approx 1 \%$.

3. Величина микродеформации $(\Delta c / c)$ слоя SBN-61 с уменьшением толщины пленки с 630 до $30 \mathrm{~nm}$ возрастала с 0.001 до 0.007 , т. е. степень дефектности пленки $\mathrm{SBN}-61$ возрастала.

4. Диэлектрические измерения пленок SBN-61 с $h=630 \mathrm{~nm}$ подтвердили наличие в них сегнетоэлектрических свойств при комнатной температуре, а также свидетельствовали о наличии внутреннего поля в пленках и достаточно высокой диэлектрической управляемости ( 40\% при $U=90 \mathrm{kV} / \mathrm{cm})$.

5. Полученные результаты целесообразно использовать при разработке функциональных материалов на основе тонких пленок SBN-61, выращенных на подложке $\mathrm{MgO}(001)$.

\section{Финансирование работы}

Работа выполнена в рамках реализации госзадания ЮНЦ РАН (тема № госрегистрации 01201354247) и гранта Президента РФ № МК-678.2020.2.

\section{Конфликт интересов}

Авторы заявляют, что у них нет конфликта интересов.

\section{Список литературы}

[1] J. Schefer, D. Schaniel, V.Y. Pomjakushin, U. Stuhr, V. Petricek, T. Woike, M. Wöhlecke, M. Imlau. Phys. Rev. B 74, 134103 (2006).

[2] T. Woike, V. Petricek, M. Dusek, N.K. Hansen, P. Fertey, C. Lecomte, A.V. Arakcheeva, G. Chapuis, M. Imlau, R. Pankrath. Acta Crystallograph. B 59, 28 (2003).

[3] Ю.С. Кузьминов. Сегнетоэлектрические кристаллы для управления лазерным излучением. Наука, М. (1982). $400 \mathrm{c}$.

[4] P.R. Willmott, R. Herger, B.D. Patterson, R. Windiks. Phys. Rev. B 71, 144114 (2005).
[5] M. Cuniot-Ponsard, J.M. Desvignes, B. Ea-Kim, E. Leroy. J. Appl. Phys. 93, 1718 (2003).

[6] Y.B. Yao, W.C. Liu, C.L. Mak, K.H. Wong, H.L. Tam, K.W. Cheah. Thin Solid Films 519, 52 (2010).

[7] Д.В. Стрюков, В.М. Мухортов, С.В. Бирюков, Ю.И. Головко. Наука Юга России 13, 1, 18 (2017).

[8] Д.В. Стрюков, А.В. Павленко. ПЖТФ 45, 23 (2019).

[9] В.Б. Широков, А.В. Павленко, Д.В. Стрюков, Ю.В. Ревинский. ФТТ 60, 993 (2018).

[10] А.В. Павленко, Ю.А. Кудрявцев, Д.В. Стрюков, А.С. Анохин, А.П. Ковтун, Б.Я. Севастьянов. Неорган. материалы. 55, 187 (2019).

[11] A.R. Stokes, A.J.C. Wilson. Proc. Phys. Soc. 56, 174 (1944).

[12] M. Volmer, A. Weber. Z. Phys. Chem. 119, 277 (1926).

[13] В.М. Мухортов, Ю.И. Юзюк. Гетероструктуры на основе наноразмерных сегнетоэлектрических пленок: получение, свойства и применение. Изд-во ЮНЦ РАН, Ростов н/Д (2008) 224 c

[14] В.В. Осипов, Д.А. Киселев, Е.Ю. Каптелов, С.В. Сенкевич, И.П. Пронин. ФТТ 57, 9, 1748 (2015).

[15] Т.С. Черная, Б.А. Максимов, Т.Р. Волк, Л.И. Ивлева, В.И. Симонов. ФТТ 42, 1668 (2000).

Редактор К.В. Емцев 